\title{
THERMAL PERFORMANCE ANALYSIS OF OPAQUE FACADES FOR THE DIFFERENT THICKNESS
}

\author{
Sridhar. ${ }^{1}$, C.S.Venkatesha ${ }^{2}$ \\ ${ }^{I}$ Mtech (MTP) Student, UBDTCE, Davangere \\ ${ }^{2}$ Professor, Dept. of Mechanical Studies, UBDTCE, Davangere
}

\begin{abstract}
Facades could be one of the ways to reduce the cooling load for buildings. In this work heat transfer analysis for different thickness facade configurations (all four sides facade of a room). From the results, it is found that there is nearly 5.8\% reduction in wall temperature for all four sided facade configuration. The thickness of façade also influence the rate of heat transfer.If the thickness of façade increases the inside façade surface temperature is decreases, that shows the thickness of façade is inversely proportion to the heat transfer. If the thickness of façade is increased that leads to reduction the temperature of façade inner surface.
\end{abstract}

\section{INTRODUCTION}

An energy crisis has become a challenging issue all over the world. More than $40 \%$ of energy consumption is due to buildings. People were and are always looking to improve indoor conditions. Cold countries are worried of keeping the space warm where as hot countries are worried of keeping the space cooler. Most of the hot countries are under developed $\&$ developing nations.

Building heat transfer is a complex process which includes all the three modes of heat transfer occurring simultaneously. Hence, the objective of the present work is how the thickness of façade effects the cooling load for building. Reducing of energy consumption due to cooling load can greatly bring positive effect in the economic growth of hot/warm countries.

\subsection{Facades}

The word "FACADES" comes from the French language literally meaning "frontage" or "face". Facades are mainly used to give good aesthetic look for buildings because of its smooth and flat surface and they can adopt any colour. Facades will also reduce the moisture problem in some regions these facades are used as sound (acoustic) insulation also.

\section{ANALYSIS DETAILS}

In present work two different configurations are studied that the room with no facades (Control) configuration. The different thickness configuration of facades is studied with all four side facade (East, West, South, North).

\subsection{Solution Details}

Building heat transfer calculations become complex because of the physics involved. It is an unsteady conjugate heat transfer problem, and involves radiation heat transfer also. We solve the problems in two different ways. They are
1. Solving by heat balancing method.

2. Solving by simple heat transfer equations.

Assumptions made in the analysis are

$\circ \quad$ Reflection from surrounding ground is neglected

- The building walls are parallel to East, West, south and North direction.

- Here we are select clear glass plastic as a façade material.

- The thermal properties are uniform in both wall and facades

\subsection{Solving by Simple Heat Transfer Equations}

The following steps are involved in calculation.

1. Here we assuming the following geometrical dimension for analysis select $4 \mathrm{~m} * 4 \mathrm{~m} * 4 \mathrm{~m}$ height, width and length respectively. For facades we choose with 4 side facades configuration.

2. Collecting the data from Wed Co (1).

3 . The solar radiation on side walls and ceiling are taken from Nielsen (2).

4. Calculate the convection heat flux by using equations.

5. Calculate the external and internal temperatures of facades in same way.

\section{GOVERNING EQUATION}

\subsection{Continuity Equation}

$$
\frac{\delta(\rho \mathrm{U})}{\delta t}+\boldsymbol{\nabla}(\boldsymbol{\rho} U)=0
$$

\subsection{Conjugate Heat Transfer}

Solid region conservation of energy equation solved for heat transfer due to conduction,

$$
\frac{\delta(\rho C p T)}{\delta t}=\nabla(K \nabla T)
$$


Where $\rho, \mathrm{Cp}$, and $\mathrm{K}$ are the density, specific heat, and thermal conductivity of the solid, respectively.

\subsection{Radiation Transport}

In radiation modeling number of particles (photons) are considered, which passes through the fluid domain and there is no interaction between the fluid and the radiation particles and their path is tracked thought the solution. In radiation modeling radiation transport equations are solved.

The spectral radioactive transport equation (RTE) can be written as

$$
\begin{aligned}
\frac{d I_{v}(\bar{r}, \bar{s})}{d s}=\left(-\left(K_{a v}+K_{s v}\right) I_{v}(\bar{r}, \bar{s})+K_{a v} I_{b}(v, T l)\right. \\
\left.+\frac{K_{s v}}{4 \pi} \int_{0}^{4 \Pi} d l_{v}\left(\bar{r}, \overline{s^{\prime}}\right) \emptyset\left(\overline{s^{\prime}} \cdot \overline{s^{\prime}}\right) d \Omega^{\prime}+S\right)
\end{aligned}
$$

\subsection{Boundary Conditions}

The solar radiation on side walls and ceiling are taken from Nielsen [3] and Wed Co. The external surface of side wall/facade will exchange heat with ambient air by convection due to temperature difference between outer surface and atmospheric air.

For side walls/facades (vertical surfaces) the equation governing convection loss is

$$
\mathrm{q}_{\text {convection }-\mathrm{v}}=\mathrm{h}_{\mathrm{v}}\left(\mathrm{T}_{\mathrm{w}}-\mathrm{T}_{\infty}\right)
$$

Where hv is calculated using equation (4.2) which uses (4.3) and (4.4)

$$
\begin{gathered}
h v=\frac{N u K}{L} \\
\mathrm{Nu}=0.10(\mathrm{GrPr})^{.333} \\
G r v=\frac{g \beta(T w-T \infty) L^{3}}{v^{2}}
\end{gathered}
$$

Also we can calculate the heat transfer coefficient by equation. That is

$$
\begin{array}{ll}
\mathrm{h}=5.6+(4 * \mathrm{~V}) & \text { for } \mathrm{V} \leq 5 \mathrm{~m} / \mathrm{sec} . \\
\mathrm{h}=7.3 * V^{0.78} & \text { for } \mathrm{V} \leq 30 \mathrm{~m} / \mathrm{sec} .
\end{array}
$$

Where $\mathrm{V}$ is wind velocity.

The boundary conditions applied are calculated from the equations 4.1 to 4.9 . The net radiation received by external wall is combination of solar radiation and sky radiation. But during day time solar radiation is dominating as compared to sky radiation and during night due temperature difference between wall/facade outer surface and sky it losses heat to the sky and is given by Hence net heat flux on side walls is given by the equation

$$
q_{\text {nightsky }}=\sigma \notin_{\text {sky }}\left(\mathrm{T}_{\text {outer }}^{4}-\mathrm{T}_{\text {sky }}^{4}\right)
$$

Where $\notin_{\text {sky }}$ given by equation (4.7) which uses (4.8)

$$
\begin{gathered}
T_{\text {sky }}=\notin^{.025} T_{\infty} \\
\notin_{\text {sky }}=0.787+\left(.0764 \log \left(\frac{T_{\text {dew }}}{273}\right) F_{\text {cloud }}\right. \\
F_{\text {cloud }}=1+0.024 N-.0035 N^{2}+.0028 N^{3}
\end{gathered}
$$

Hence net heat flux on side walls is given by the equation (4.9)

$$
\underset{q_{\text {wall_v }}=}{\alpha}=\underset{q_{\text {incident }}-q_{\text {convection_v } v}-q_{\text {nightsky }}-}{\boldsymbol{q}_{\text {radiation }}}
$$

\section{RESULTS}

Enclosures with four side façade following results are obtained, which are shown in figures 1 to 10

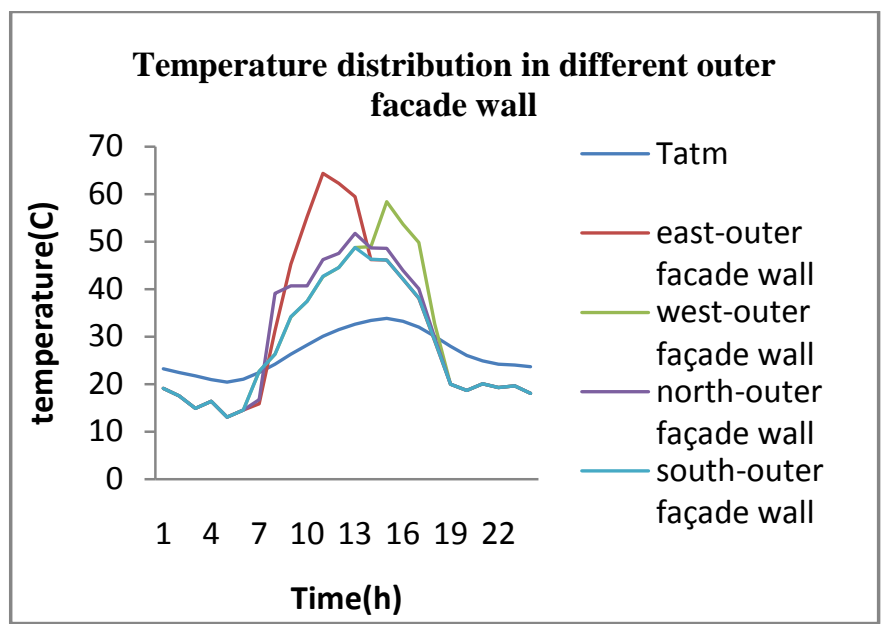

Fig1 Temperature distribution in different outer façade walls.

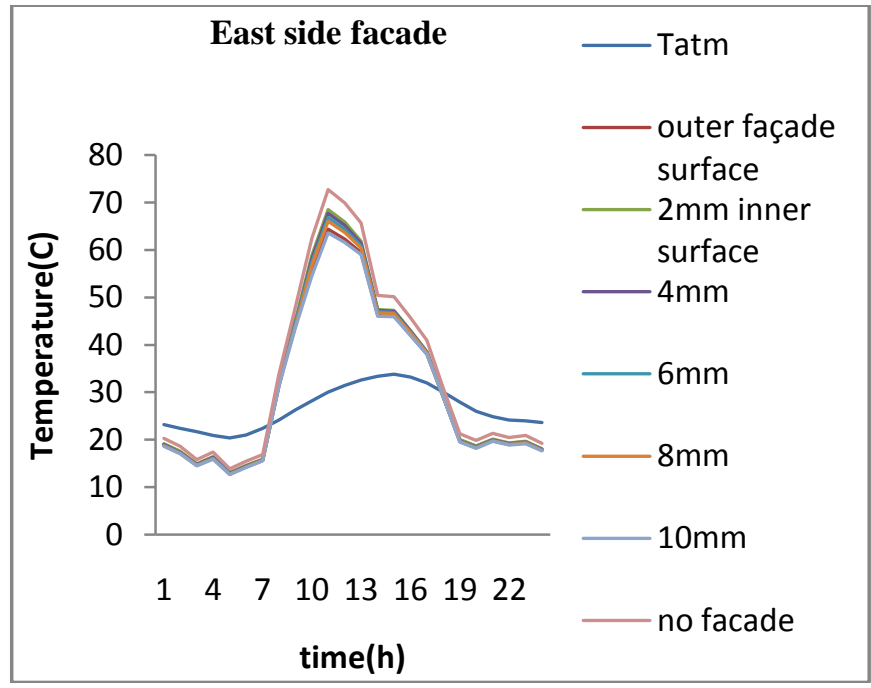

Fig2 Temperature variation in east side facades. 


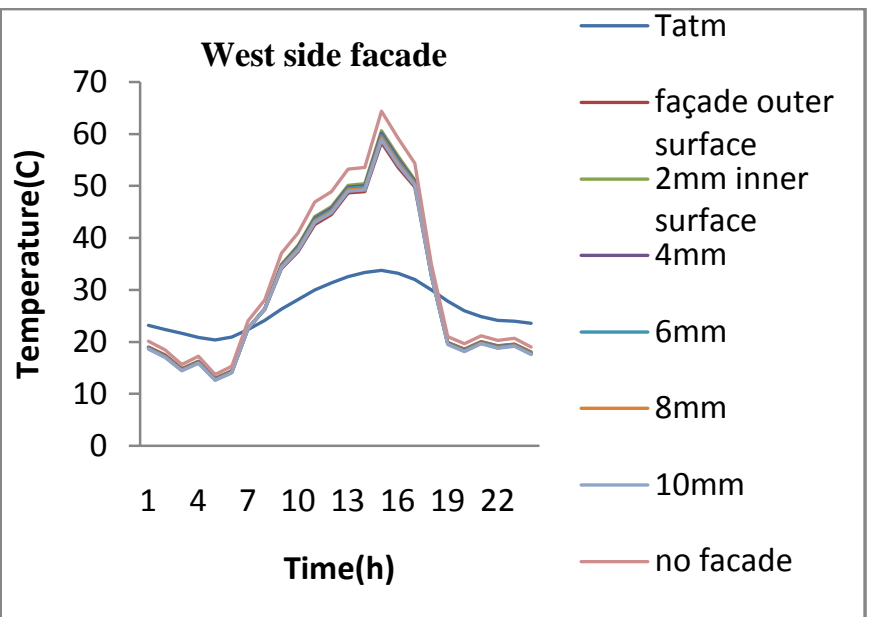

Fig3 Temperature variation in west side facades

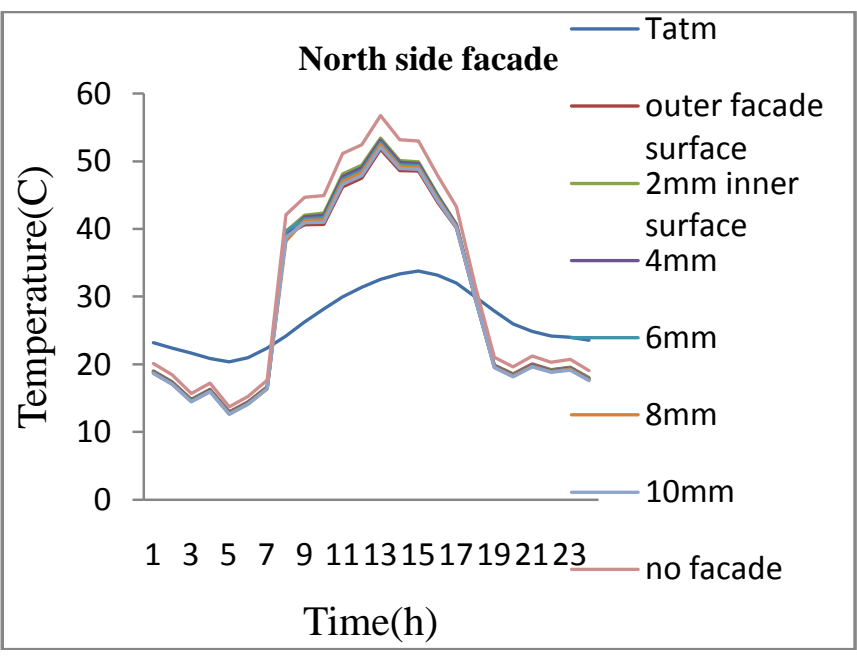

Fig4 Temperature variation in north side facades.

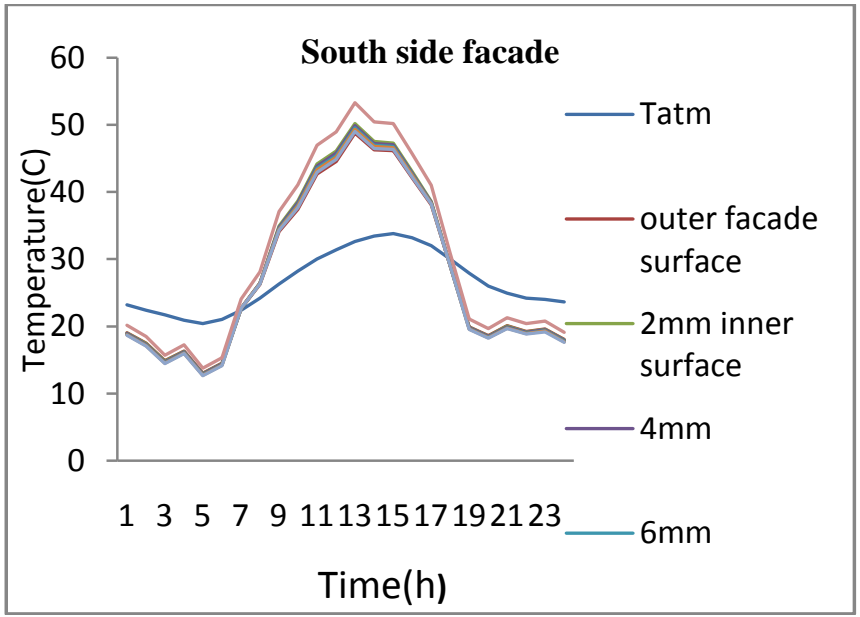

Fig5 Temperature variation in south side facades.

The figures 2 to 5 show influence of thickness on façade wall temperature for different side facades. From the results, it is found that there is $5.8 \%$ reduction in room temperature for all four sided facade configuration. . Here the effect of radiation heat flow and environmental changes like fluctuation in wind velocity is not considered. Consideration of these factors the walls temperature may change.

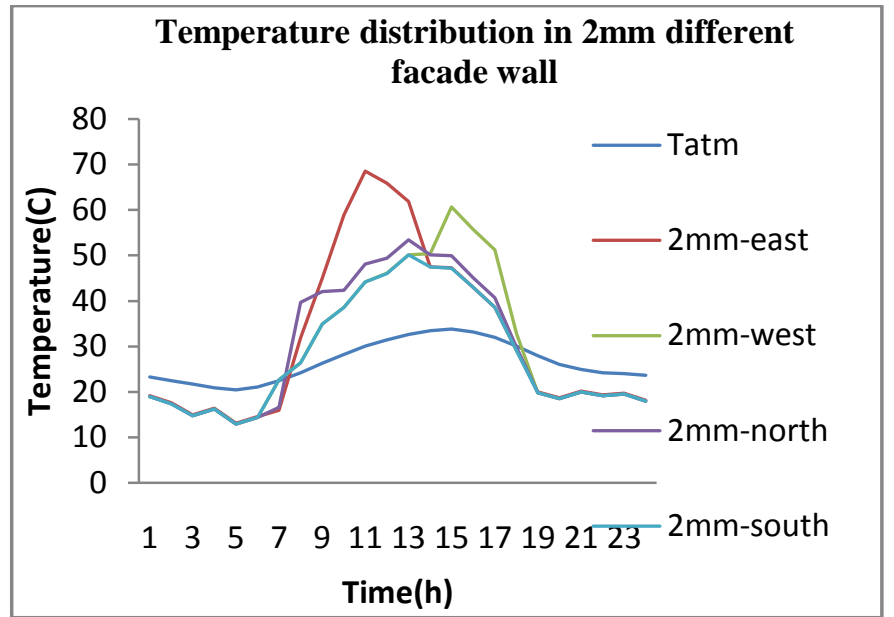

Fig6 Temperature variation in $2 \mathrm{~mm}$ (thickness) facades.

The in figure 6 the east side inner façade surface temperature is having higher temperature compare to the façade walls and the south side façade wall temperature is lesser than other façade walls.

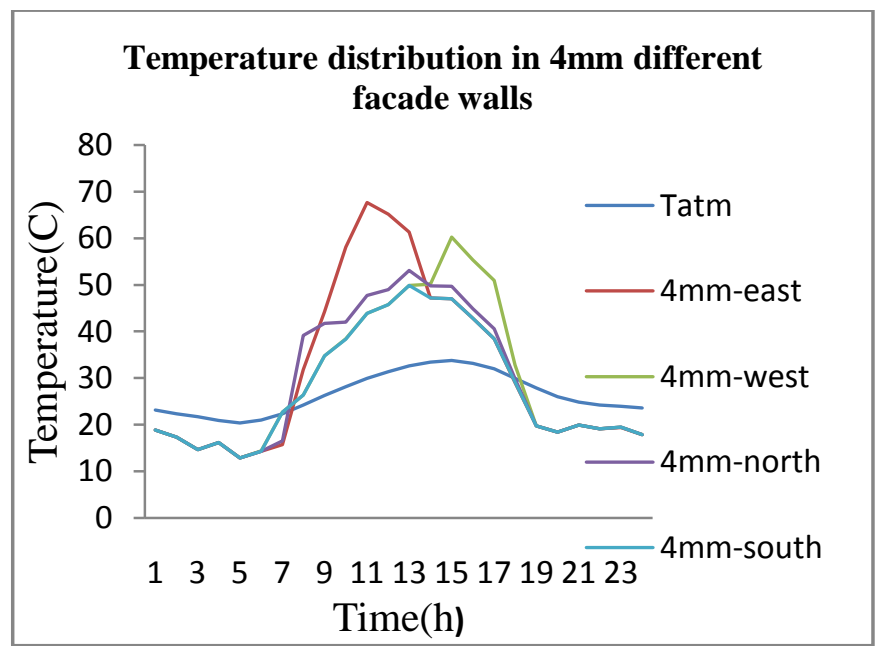

Fig7 Temperature variation in $4 \mathrm{~mm}$ (thickness) facades.

Temp of east façade > Temp of west façade > Temp of north façade > Temp of south façade

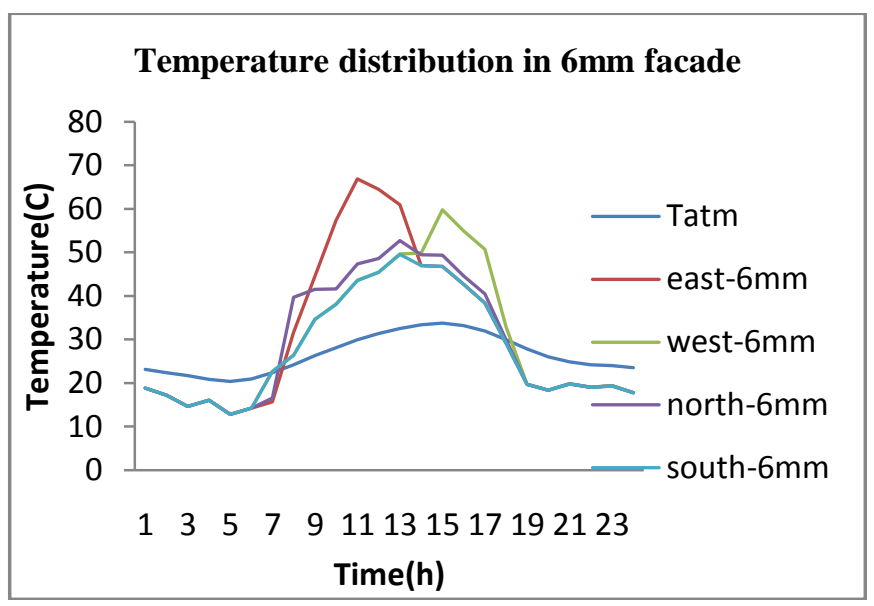

Fig8 Temperature variation in 6mm (thickness) facades. 


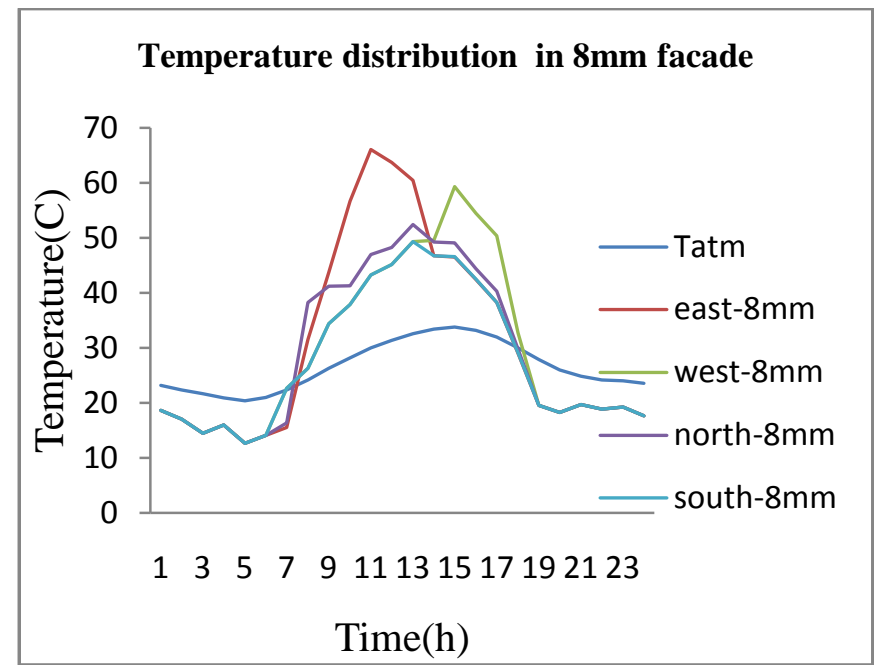

Fig9 Temperature variation in $8 \mathrm{~mm}$ (thickness) facades.

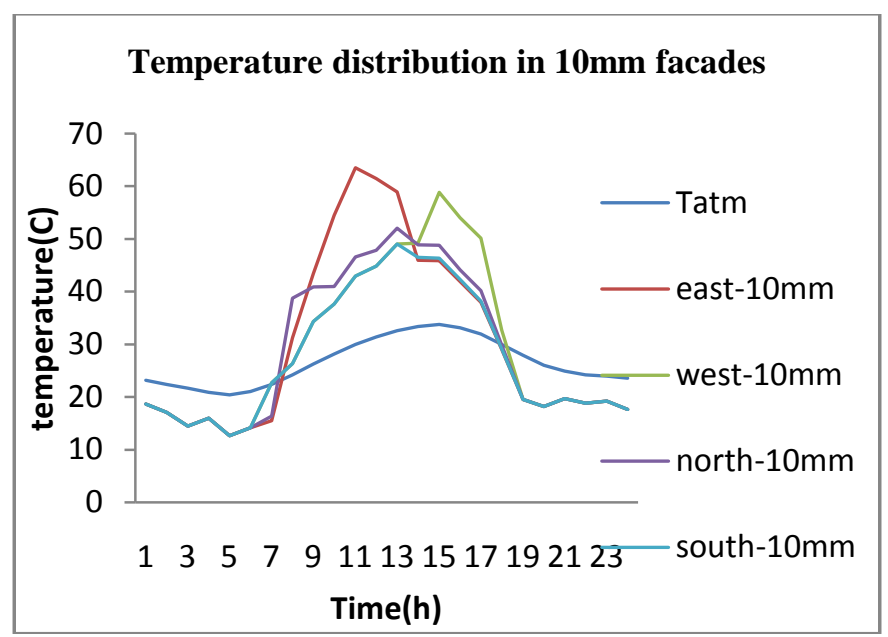

Fig10 Temperature variation in 10mm (thickness) facades.

Figure 9 shows the temperature of east side façade inner wall is more than the other façade walls because, during morning most of solar radiation falls on east side only and less amount of solar radiation falls on remaining sides of the façade walls. Afternoon onwards the west side façade wall gets more amount of heat flux. Hence, the temperature of west side façade wall is having higher temperature after $2.00 \mathrm{pm}$. South façade wall temperature is less compared to other façade walls.

\section{CONCLUSIONS}

The main objective of this work is to see the how the façade thickness influence the temperature distribution linearly throughout the thickness. The façade heat transfer calculations are very complex in nature because involvement of physics. The building heat transfer is an unsteady process in which one can observe all three mode of heat transfer. They are heat conduction, convection and radiation. Here we have to simultaneously solve the all type of heat transfer equations.

Study considered about configuration

$>$ According to paper (3) we select four side façade configurations because of its effectiveness.
From the calculations, the following conclusions could be drawn.

$>$ The thickness of façade also influence the rate of heat transfer .If the thickness of façade increases the inside façade surface temperature decreases, that shows the thickness of façade is inversely proportion to the heat transfer.

$>\quad$ If the thickness of façade is increased that leads to reduction the temperature of façade inner surface and also the installation expenses increases.

$>\quad$ If the thickness of façade is increased, that leads to unchanging the density of air flowing within the air cavity and air become motionless that causes reduction in effectiveness.

\section{SCOPE FOR FUTURE WORK}

$>$ For this work there is no experimental data available. Hence one can carry out real experiments on the same.

$>$ We can carry out same analysis for the façade with regular curved surfaces. They may increase the heat transfer rate by creating the turbulent flow of air with in the air cavity.

$>$ Calculate the performance for different façade materials is possible.

\section{ACKNOWLEDGEMENT}

I would like to express my gratitude to our guide Dr. C.S. Vekatesha for the continuous support to this project work. Furthermore I would like to thank Dr. Madhu (Head of Department, Mechanical Engineering, GEC, K.R.Pet.) for the support on the way. Also, I like to thank Mr. Suneel Patil to give the useful suggestion to complete my work. I will be grateful everyone one who help me directly and indirectly.

\section{REFERENCES}

[1] Nielsen, Toke Rammer, Svend Svendsen., "Harmoniseringafgrundlaget for beregningafenergitilskudfravindure", BYG-DTU Dammarks Tekniske Universitet, Sagsrapport BYGDTU SR-03-03, 2003.

[2] WeDCoDatabase ${ }^{\circledR}$ Ver: 2.1, Weather and Design Conditions for India, Tata Energy Research Institute, for ASHRAE.

[3] Mr. SuneelPatil ("Thermal Performance of Opaque Facades for Buildings to Reduce

[4] Cooling Loads"- 2012 - 2013(VTU, Belgaum )

[5] María José Suáreza,*, Cristina Sanjuanb, Antonio José Gutiérrez a, Jorge Pistonoa, Eduardo Blanco a(Energy evaluation of an horizontal open joint ventilated façade-Applied Thermal Engineering 37 (2012) 302e313)

[6] M. Ciampi, F. Leccese, G. Tuoni *(Ventilated facades energy performance in summer cooling of buildings- Solar Energy

[7] Cristina Sanjuan, ET. Al, "Energy performance of an open-joint ventilated façade compared with a 
conventional sealed cavity facade", International journal of solar energy, vol. 85, pp. 1851-1863, 2011.

[8] Clara balocco "simple model to study ventilated facades energy performance"- 1 October2001

[9] Heinrich Manz"Numerical simulation of heat transfer by natural convection in cavities of facade elements"

[10] J. Xama'nb, 2, G. A' lvareza, 1, L. Liraa, b, C. Estradac, "Numerical study of heat transfer by laminar and turbulent natural convection in tall cavities of facade elements" 